\title{
Do We Know the Complete Story of TPM1к Expression in Vertebrate Hearts?
}

\section{Dipak K Dube*, Patricia M. Benz, Syamalima Dube and Bernard J. Poiesz}

Department of Medicine, SUNY Upstate Medical University, 750 East Adams Street, Syracuse, NY 13210, USA

Tropomyosin (TM) is a component of myofibrils, the contractile apparati of striated muscle cells. The assembly of a myofibril involves the precise ordering of several proteins into a linear array of sarcomeres. The process is complicated further because most of these proteins have multiple isoforms. Recent demonstration of the association of TM mutations with Hypertrophic Cardiomyopathy (HCM)/Familial Hypertrophic Cardiomyopathy (FHC) [1-3] or other cardiomyopathies such as Dilated Cardiomyopathy (DCM) [4,5] and nemalin skeletal myopathy [6] in humans have spurred renewed interest in the structural/functional relationships of TM. In vertebrate striated muscle, the thin filament consists largely of actin, TM, the Troponin (Tn) complex (Tn-I, Tn-C and Tn-T), Tropomodulin (Tmod), and Leiomodin (Lmod). It is responsible for mediating $\mathrm{Ca}^{+2}$ control of contraction and relaxation. With the influx of $\mathrm{Ca}^{+2}$ in muscle cells, troponin-C binds with $\mathrm{Ca}^{+2}$ and undergoes a rapid conformational change, which causes additional conformation changes in the TM-Tn complex exposing the myosin associated ATPase activity. As a result, the free myosin associated ATPase activity hydrolyzes ATP with the release of energy that helps muscle to contract. There are four genes (designated as TPM1, TPM2, TPM3, and TPM4) for TM in vertebrates $[7,8]$ except for zebrafish where there are six TM genes [9], which generate a multitude of tissue and developmental specific isoforms through the use of different promoters, alternative mRNA splicing, and tissue specific translational control [10]. The functional significance of this diversity and how it may affect interactions with other sarcomeric proteins is not fully understood. Sarcomeric isoforms for both TPM1 and TPM2 are expressed in large mammals, including humans [11]. The protein of the sarcomeric isoform of TPM3 is not expressed in mammalian hearts. In mammals TPM4 is truncated relative to the gene found in avian [12] and amphibian species [13].

TPM1a (one of the nine alternatively spliced isoforms of the TPM1 gene) has been identified as the major sarcomeric isoform in vertebrate hearts [8]. We were the first to identify and characterize an alternatively spliced sarcomeric isoform of the TPM1 gene, which is expressed in cardiac tissues in different vertebrates [14,15] including humans [16]. This novel isoform, designated TPM1 $\kappa$, contains exons 1a, 2a (instead of $2 \mathrm{~b}$ as in TPM1 $\mathrm{a}$ ), 3, 4, 5, 6b, 7, 8 and $9 \mathrm{a} / \mathrm{b}$ (Figure 1). The functional significance of this novel isoform is beginning to emerge.

TPM1 $\alpha$ constitutes $>86 \%$ of the total sarcomeric tropomyosin in mammalian cardiac muscle and plays an essential role in the cardiac

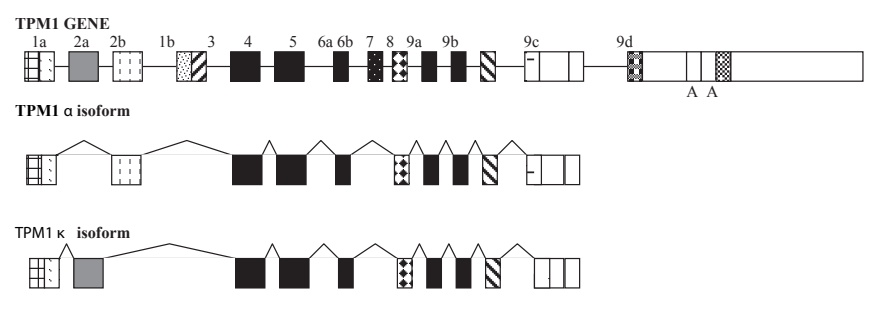

Figure 1: Two sarcomeric splice variants of the TPM1 gene. contractility in mammals. Ectopic expression of TPM1 1 with various missense mutations implicated in human FHC (e.g. D175, D180G, etc) $[17,18]$ and in DCM (E54K) in transgenic (TG) mice helped in developing mouse models for the diseases [19].

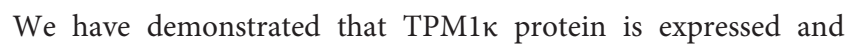
incorporated into organized myofibrils in the heart and skeletal muscle of Mexican axolotls [20], which is an ideal animal model for studying structural/functional relationships of TM. The cardiac mutant of the Mexican axolotl lacks organized cardiac myofibrils and its heart does not beat [21]. Exogenous supply of TPM1a or TPM1к promotes myofibril formation in mutant axolotl hearts in situ. Using isoform specific antisense oligonucleotide we have shown that although the expression level of TPM1 $\kappa$ protein is low (5-6\% of the total sarcomeric tropomyosin) compared to TPM1 1 (80\%), it is essential for the cardiac contractility and cardiac myofibrillogenesis in the ventricle of axolotl heart in situ [22].

TPM1к protein is expressed and incorporated into organized myofibrils in human hearts and its level is increased in hearts in DCM and Heart Failure (HF) patients [23]. In humans TPM1к is expressed in heart but not in skeletal muscle. To investigate the role of TPM1 $\kappa$ in myofibrillogenesis in the mammalian system, Rajan et al. [23] generated TG mice overexpressing TPM1 1 protein in a cardiac specific manner. None of the founder TPM1к mice nor their progeny demonstrated differences in either heart weight or in life span when compared with Non-Transgenic controls (NTG). An over-expression

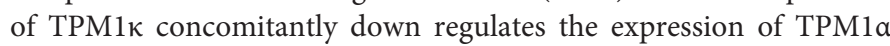
so that the total sarcomeric TM level remains constant. Histological analyses revealed no detectable changes in microscopic cellular morphology. However, echocardiographic analyses showed that mice

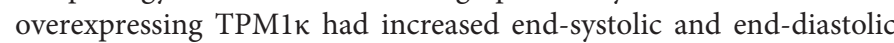
left ventricular dimensions. Furthermore, biochemical and biophysical studies demonstrated less structural stability, weak actin-binding

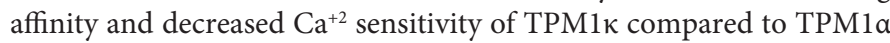
myofilament. Further studies are needed to understand whether the small increase in TPM1 $\kappa$ expression [23] in human heart failure represents a partial compensatory mechanism aimed at reducing the $\mathrm{Ca}^{+2}$ sensitivity of the thin filament toward the nonfailing state [24].

Two important issues should be considered:

*Corresponding author: Dipak K Dube, Department of Medicine, SUNY Upstate Medical University, 750 East Adams Street, Syracuse, NY 13210, USA; Fax: 1-650-618-1414; E-mail: dubed@Upstate.edu

Received June 14, 2012; Accepted June 18, 2012; Published June 20, 2012

Citation: Dube DK, Benz PM, Dube S, Poiesz BJ (2012) Do We Know the Complete Story of TPM1א Expression in Vertebrate Hearts? J Cytol Histol 3:e104. doi:10.4172/2157-7099.1000e104

Copyright: ( 2012 Siddiqui MT. This is an open-access article distributed under the terms of the Creative Commons Attribution License, which permits unrestricted use, distribution, and reproduction in any medium, provided the original author and source are credited. 
1. Physiological experiments should be performed with TG mice

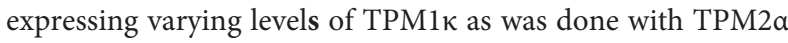
[25].

2. The TG mouse model for FHC mutations in TPM1 (other than in exon 2) was carried out with only TPM1a. However, in human hearts both TPM1 $\alpha$ and TPM1 $\kappa$ are expressed. The FHC mutation(s) (D175N, E180G, etc) and DCM mutation such as $\mathrm{D} 230 \mathrm{~N}$ are present in both sarcomeric isoforms of the TPM1 gene. Over expression of TPM1 $\kappa$ in the heart leads to decreased $\mathrm{Ca}^{+2}$ sensitivity with no change in maximum developed tension. On the contrary, over expression of D175N.TPM1a or D180G. TPM1 $a$ leads to an increased $\mathrm{Ca}^{+2}$ sensitivity. The ideal FHC mouse model should be the over-expression of both TPM1a and TPM1 $\kappa$ isoforms with the same FHC mutation.

The binding affinity of TPM1 $\kappa$ with actin filament in vitro is very low compared to that of TPM1a. In fact, it fails to bind with F-actin in vitro in the absence of the troponins. However, the dynamics of TPM1 $\kappa$ in avian myotubes in vivo is comparable to that of TPM1a [26]. Also, ectopic expression of either TPM1 $\kappa$ or TPM1 1 in non-beating cardiac mutant hearts, which lack organized myofibrils, induces organized myofibrils and helps the non-beating hearts to beat in situ [27]. It is to be noted that although mutant axolotl hearts lack sarcomeric tropomyosin, they contain troponins. Of the three troponins, only Tn-T binds with TM directly. The isoform diversity of cardiac troponin-T in the developing, adult, and failing heart in humans is well documented [28]. Our RT-PCR results [16] and western blot analysis with exon 2a -specific antibody (unpublished) suggest that the expression of TPМ1 $\kappa$ is higher in the fetal human heart. More detailed analyses on the interaction of different troponin-T with TPM1א and TPM1 $\alpha$ is an essential prerequisite for understanding the role of TPM1 $\kappa$ in the developing and diseased heart (like HF patients).

In terminally differentiated cells, such as cardiomyocytes, there is a need for adaptation to changing environments. Isoform diversity of various myofibrillar proteins may facilitate such adaptation. Conversely, increased expression of certain isoform(s), such as TPM1 $\kappa$, could be part of the pathogenesis of cardiac diseases, which may well be a reason for the restricted / limited translation of the TPM1 transcripts in vertebrate hearts [20,23]. Although enormous progress has been made with mouse models on the functional aspects of various TM isoforms, further work needs to be done developing and utilizing TPM1к-tissue-specific knockout mice. Such experimentation(s) would

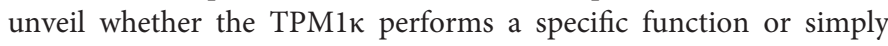
emerges due to an infidelity in the post-transcriptional process in the gene expression machinery.

\section{Acknowledgement}

The work was partly supported by a grant from Health Science Foundation at Syracuse, Inc.

\section{References}

1. MArtin AJ, Roberts R (2001) The molecular genetic basis for Hypertrophic cardiomyopathy. J Mol Cell Cardiol 33: 655-670.

2. Thierfelder L, Watkins H, MacRae C, Lamas R, McKenna W, et al. (1994) Alphatropomyosin and cardiac troponin $\mathrm{T}$ mutations cause familial hypertrophic cardiomyopathy: a disease of the sarcomere. Cell 77: 701-712.

3. Thierfelder L, Watkins H, MacRae C, Lamas R, McKenna W, et al. (1995) A de novo mutation in alpha-tropomyosin that causes hypertrophic cardiomyopathy. Circulation 91: 2302-2305.

4. Olson TM, Kishimoto NY, Whitby FG, Michels VV (2001) Mutations that alter the surface charge of alpha-tropomyosin are associated with dilated cardiomyopathy. J Mol Cell Cardiol 33: 723-732.

5. Lakdawala NK, Dellefave L, Redwood CS, Sparks E, Cirino AL, et al. (2010) Familial dilated cardiomyopathy caused by an Alpha-tropomyosin mutation: the distinctive natural history of sarcomeric dilated cardiomyopathy. J Am Col Cardiol 55: 320-329.

6. Michele DE, Coutu P, Metzger JM (2002) Divergent abnormal muscle relaxation by hypertrophic cardiomyopathy and nemaline myopathy mutant tropomyosins. Physiol Genomics 9: 103-111.

7. Gunning P, O'neill G, Hardeman E (2008) Tropomyosin-based regulation of the actin cytoskeleton in time and space. Physiol Rev 88: 1-35.

8. Lees-Miller JP, Helfman DM (1991) The molecular basis for tropomyosin isoform diversity. Bioessays 13: 429-437.

9. Schevzov G, Whittaker SP, Fath T, Lin JJ, Gunning PW (2011) Tropomyosin isoforms and reagents. Bioarchitecture 1: 135-164.

10. Jagatheesan G, Rajan S, Wieczorek DF (2010) Investigations into tropomyosin function using mouse models. J Mol Cell Cardiol 48: 893-898.

11. Pieples K, Wieczorek DF (2000) Tropomyosin 3 increases striated muscle isoform diversity. Biochemistry 39: 8291-8297.

12. Fleenor DE, Hickman KH, Lindquester GJ, Devlin RB (1992) Avian cardiac tropomyosin gene produces tissue-specific isoforms through alternative RNA splicing. J Muscle Res Cell Motil 13: 55-63.

13. Hardy S, Thézé N, Lepetit D, Allo MR, Thiebaud P (1995) The Xenopus laevis TM-4 gene encodes non-muscle and cardiac tropomyosin isoforms through alternative splicing. Gene 156: 265-270.

14. Luque EA, Spinner BJ, Dube S, Dube DK, Lemanski LF (1997) Differentia expression of a novel isoform of alpha-tropomyosin in cardiac and skeletal muscle of the Mexican axolotl (Ambystoma mexicanum). Gene 185: 175-180.

15. Zajdel RW, Denz CR, Lee S, Dube S, Ehler E, et al. (2003) Identification, characterization, and expression of a novel alpha-tropomyosin isoform in cardiac tissues in developing chicken. J Cell Biochem 89: 427-439.

16. Denz CR, Narshi A, Zajdel RW, Dube DK (2004) Expression of a novel cardiacspecific tropomyosin isoform in humans. Biochem Biophys Res Commun 320: 1291-1297.

17. Muthuchamy M, Pieples K, Rethinasamy P, Hoit B, Grupp IL, et al. (1999) Mouse model of a familial hypertrophic cardiomyopathy mutation in alphatropomyosin manifests cardiac dysfunction. Circ Res 85: 47-56.

18. Geisterfer-Lowrance AA, Christe M, Conner DA, Ingwall JS, Schoen FJ, et al (1996) A mouse model of familial hypertrophic cardiomyopathy. Science 272 731-734.

19. Rajan S, Ahmed RP, Jagatheesan G, Petrashevskaya N, Boivin GP, et al (2007) Dilated cardiomyopathy mutant tropomyosin mice develop cardiac dysfunction with significantly decreased fractional shortening and myofilament calcium sensitivity. Circ Res 101: 205-214.

20. Thomas A, Rajan S, Thurston HL, Masineni SN, Dube P, et al. (2010) Expression of a novel tropomyosin isoform in axolotl heart and skeletal muscle. J Cell Biochem 110: 875-881.

21. Lemanski LF (1973) Morphology of developing heart in cardiac lethal mutant Mexican axolotls, Ambystoma mexicanum. Dev Biol 33: 312-333.

22. Zajdel RW, Denz CR, Narshi A, Dube S, Dube DK (2005) Anti-sense-mediated inhibition of expression of the novel tropomyosin isoform TPM1kappa disrupts myofibril organization in embryonic axolotl hearts. J Cell Biochem 95: 840-848.

23. Rajan S, Jagatheesan G, Karam CN, Alves ML, Bodi I, et al. (2010) Molecular and functional characterization of a novel cardiac specific human tropomyosin isoform. Circulation 121: 410-418.

24. Vanburen P, Palmer BM (2010) Cooperative activation of the cardiac myofilament: the pivotal role of tropomyosin. Circulation 121: 351-353.

25. Prabhakar R, Boivin GP, Hoit B, Wieczorek DF (1999) Rescue of high expression beta-tropomyosin transgenic mice by 5-propyl-2-thiouracil. Regulating the alpha-myosin heavy chain promoter. J Biol Chem 274: 29558-29563.

26. Wang J, Sanger JM, Kang S, Thurston H, Abbott LZ, et al. (2007) Ectopic expression and Dynamics of TPM1alpha and TPM1kappa in myofibrils of avian myotubes. Cell Motil Cytoskeleton 64: 767-776. 
Citation: Dube DK, Benz PM, Dube S, Poiesz BJ (2012) Do We Know the Complete Story of TPM1к Expression in Vertebrate Hearts? J Cytol Histol 3:e104. doi:10.4172/2157-7099.1000e104

Page 3 of 3

27. Zajdel RW, Sanger JM, Denz CR, Lee S, Dube S, et al. (2002) A novel striated tropomyosin incorporated into organized myofibrils of cardiomyocytes in cell and organ culture. FEBS Lett 520: 35-39.
28. Anderson PA, Greig A, Mark TM, Malouf NN, Oakeley AE, et al. (1995) Molecular basis of human cardiac troponin $T$ isoforms expressed in the developing, adult, and failing heart. Circ Res 76: 681-686. 